\title{
Views of fathers in Ireland on the experience and challenges of having a breast-feeding partner
}

Annemarie Bennett

Technological University Dublin, abennet@tcd.ie

Daniel McCartney

Technological University Dublin, daniel.mccartney@tudublin.ie

John Kearney

Technological University Dublin, john.kearney@tudublin.ie

Follow this and additional works at: https://arrow.tudublin.ie/scschbioart

Part of the Biology Commons, Maternal and Child Health Commons, and the Women's Health Commons

\section{Recommended Citation}

Annemarie E. Bennett, Daniel McCartney, John M. Kearney, Views of fathers in Ireland on the experience and challenges of having a breast-feeding partner, Midwifery, Volume 40, 2016, Pages 169-176, ISSN 0266-6138, DOI: 10.1016/j.midw.2016.07.004.

This Article is brought to you for free and open access by the School of Biological Sciences at ARROW@TU Dublin. It has been accepted for inclusion in Articles by an authorized administrator of ARROW@TU Dublin. For more information, please contact arrow.admin@tudublin.ie, aisling.coyne@tudublin.ie,gerard.connolly@tudublin.ie. Funder: Technological University Dublin 


\title{
Views of fathers in Ireland on the experience and challenges of having a breast-feeding partner
}

\author{
Annemarie E. Bennett, BSc (Research Dietitian)*, \\ Daniel McCartney, BSc, MSc, PhD (Lecturer in Human Nutrition and Dietetics), \\ John M. Kearney, BSc, PhD (Lecturer in Nutrition and Epidemiology)
}

School of Biological Sciences, Dublin Institute of Technology, Kevin Street, Dublin 8, Ireland

\section{A R T I C L E I N F O}

\section{Article history:}

Received 26 January 2016

Received in revised form

17 June 2016

Accepted 3 July 2016

\section{Keywords:}

Fathers

Breast feeding

Milk feeding

Breast feeding in public

Breast feeding promotion

Ireland

\begin{abstract}
A B S T R A C T
Objective: this study investigated the relationship between fathers and breast feeding in Ireland.

Design and method: a cross-sectional semi-quantitative questionnaire with closed-ended and openended questions was posted to 1398 men with an Irish partner who had given birth 4-7 months previously. Fathers who specified that their partner breast fed their last or only child were questioned about their: influence on the breast feeding decision; ability to assist with breast feeding challenges; preferred type of information on breast feeding; perceived advantages and disadvantages to breast feeding; and views on breastfeeding in public. Data from closed-ended questions on breast feeding were presented using frequencies and associated percentages. Answers to open-ended questions on breast feeding were categorised into themes using content analysis. Each theme was assigned a numerical code and the themes developed were quantitatively counted and presented as frequencies and percentages.

Findings: of the 583 respondents (42\% response rate), 417 (71.5\%) had a partner who had breast-fed their last or only child. Most of the 417 fathers were employed $(95.7 \%, n 399)$, college-educated $(76.7 \%, n 320)$ and married $(87.8 \%, n 366)$. Most $(75.5 \%, n 315)$ fathers were involved in the breast feeding decision. The majority $(77.5 \%, n 323)$ of fathers were unprepared for at least one aspect of breast feeding, most commonly that their partner encountered difficulties in establishing breast feeding. Of those fathers with a partner who experienced difficulties with breastfeeding $(56.8 \%, n 237)$, half $(49.4 \%, n 117)$ were unable to help their partner to overcome her breast feeding difficulties. Two-fifths $(41.0 \%, n 133)$ of fathers felt deprived of bonding time. Almost one in ten $(9.4 \%, n 39)$ fathers felt uncomfortable with an unrelated woman breast feeding in public, and this increased to three in ten or one third $(34.3 \%, n 143)$ if the woman in question was their partner.

Key conclusion: while fathers in a well-educated and socially advantaged sample are largely supportive of breast feeding, significant challenges remain in terms of their ability to support breast feeding in an informed and practical manner.

Implications for practice: women who are practically and emotionally supported by their partners are more likely to successfully breast feed, but the male perspective of breast feeding in Ireland has been given little attention. This study supports earlier and more effective engagement of fathers throughout the breast feeding process, and highlights areas of concern with respect to the role of fathers in breast feeding.
\end{abstract}

(c) 2016 Elsevier Ltd. All rights reserved.

\section{Introduction}

Ireland has had a breast feeding policy since 1994 (Department of Health, 1994), participated in the WHO-UNICEF Baby-Friendly Hospital Initiative since 1998, and implemented a national breast

\footnotetext{
* Corresponding author.

E-mail addresses: abennet@tcd.ie (A.E. Bennett), daniel.mccartney@dit.ie (D. McCartney), john.kearney@dit.ie (J.M. Kearney).
}

feeding strategy since 2005 (Department of Health and Children, 2005). Despite these measures, and despite the widely promoted physical and emotional benefits of breastfeeding for mother and infant (Gartner et al., 2005), rates of breast feeding initiation and duration in Ireland remain well below those of our European counterparts (Brick and Nolan, 2013).

Ireland has not had a breast feeding culture for several generations (Curtin, 1954; Kevany et al., 1975; McSweeney and Kevany, 1982; Fitzpatrick et al., 1994; Brick and Nolan, 2013). As such, 
the skill of breast feeding has been lost to the social and cultural network of many women in Ireland. Health professionals have been identified as important to the success of breast feeding (Begley et al., 2008; Brown et al., 2011; Tarrant et al., 2011), but with shorter hospital stays, the potential contribution of a mother's family network to the success of breast feeding cannot be dismissed.

The support offered by a woman's partner affects her decision to initiate and continue breast feeding (Scott et al., 2001; Pisacane et al., 2005; Pontes et al., 2008; Susin and Giugliani, 2008). The only Irish study to date which assesses the attitude of fathers to breast feeding (Kenosi et al., 2011) reported that while most of the fathers surveyed discussed infant feeding methods with their partner, only a third felt that it was a shared decision between both parents. Brown and Davies (2014) similarly reported that while fathers were positive about breast feeding, most ultimately referred to breast feeding as their partner's choice. It is inarguably important that a woman's autonomy to choose is respected. However, fathers who are removed from the breast feeding process can feel frustrated, alienated and helpless when it comes to supporting the needs of their breast-feeding partner and infant (Barclay and Lupton, 1999; Goodman, 2005; Pontes et al., 2009; Brown and Davies, 2014). Therefore, it's also important that fathers feel included in, and necessary to, the breastfeeding process from the outset.

Several studies have investigated reasons why mothers in Ireland never initiate, or discontinue, breast feeding. These reasons most commonly relate to the perceived negative impact of breast feeding on lifestyle, maternal fatigue, difficulty with breast feeding techniques and perceived milk insufficiency (Begley et al., 2008; Tarrant et al., 2009, 2011; Layte and McCrory, 2014). Therefore, mothers in Ireland often avoid or discontinue breast feeding due to technical difficulties and inadequate practical and emotional support.

The results of studies investigating the impact of paternal involvement on breast feeding have been somewhat mixed to date. However, most have shown that supportive paternal involvement has a significant positive impact on some aspect of breast feeding, whether it is initiation (Wolfberg et al., 2004), feeding on discharge (Scott et al., 2001; Tarrant et al., 2011), duration (Pisacane et al., 2005; Tarrant et al., 2011; Maycock et al., 2013), or coping with breast feeding difficulties (Pisacane et al., 2005).

The Irish study by Kenosi et al. (2011) reported that only $55.2 \%$ of fathers had enough information on breast feeding. Irish women who breast feed are in the minority from the early postpartum period, with only $42.5 \%$ of Irish mothers doing any breast feeding on discharge from hospital (Layte and McCrory, 2014). If breast feeding rates are to increase, a better understanding of male attitudes and needs around breast feeding is needed to help men to offer adequate technical, practical and emotional support to their breast-feeding partners.

To the authors' knowledge, only one study (Kenosi et al., 2011) has been conducted to date on the attitude of fathers in Ireland towards breastfeeding. This study had a small sample of 67 fathers who answered the study questionnaire within two days of the birth of their child. As such, very little is known about the experience of fathers in Ireland with breast feeding. Much work remains to be done to increase Irish breast feeding rates; this work must include recognition of the role that fathers can play as cornerstones of breast feeding support. Therefore, this study aimed to gain insight into the relationship between men and breast feeding in Ireland, by investigating the:

- Role of fathers in the breast feeding decision;

- Aspects of breast feeding for which fathers felt unprepared;

- Perceived advantages and disadvantages to having a breastfeeding partner; and

- Views of fathers on breast feeding in public.

\section{Methodology}

Ethical approval for this study was obtained from the Coombe Women and Infants University Hospital and Dublin Institute of Technology.

Design

A cross-sectional semi-quantitative postal questionnaire was used in this study.

\section{Population targeted}

The male partners of women who had given birth in the previous 4-7 months in the Coombe Women and Infants University Hospital in Dublin, Ireland, were targeted.

A list of women of Irish nationality who delivered a healthy live infant between March and September 2014 was obtained. From this, men were targeted if they were listed as next-of-kin, designated as a spouse or partner, and living at the same address as the patient.

In light of the low breast feeding rate amongst Irish mothers at 6 months post partum (Gallagher et al., 2015), questionnaires were sent to fathers with infants aged 4-7 months, in order to obtain a more accurate picture of breast feeding in the postpartum period.

\section{Postal questionnaire}

The semi-quantitative questionnaire used in this study was a postal questionnaire which was anonymously returned. The questionnaire contained 10 closed-ended and open-ended questions on breast feeding, and it was piloted with 20 male partners of women who were participating in a separate study in the Coombe Women and Infants University Hospital. From the feedback provided by respondents during the pilot, no questions were changed but minor adjustments were made to the layout of the questionnaire to enhance its clarity and accessibility for those who received it by post.

Fathers with partners who had breast-fed their last (or only) child were asked four closed-ended questions on:

- Their role in the decision to breast feed: If a father stated that he had been involved in the breast feeding decision, he had to select whether he had encouraged, discouraged or had been ambivalent about breast feeding when the decision on milk feeding was being made.

- Useful sources of information on breast feeding: Fathers had to tick their most useful sources of breast feeding from a list which included: their partner, lactation consultant, midwife, public health nurse, family member and internet. If needed, fathers could add a source which was not included on the predefined list.

- Their ability to assist with the challenges of breast feeding: Fathers had to choose from one of three options: (1) My partner had no difficulty with breast feeding; (2) I had enough information to help my partner with breast feeding difficulties; or (3) I did not have enough information to help my partner with breast feeding difficulties.

- Preferred bonding activities with a breast-fed infant: A list of bonding activities was provided (e.g. bathing infant, changing infant), from which fathers could choose their preferred bonding activity or to which they could add their own bonding activities.

Four open-ended questions obtained data on: aspects of breast feeding for which fathers felt unprepared; information on breast 
feeding information which fathers would have liked to have had in the antenatal period; and perceived advantages and disadvantages to having a breast-feeding partner.

A photograph of a woman discreetly breast feeding was also shown. Fathers were asked what they would be likely to feel should they see a woman unrelated to them feeding in this way in everyday life. The list of potential reactions included: gladness, respect, surprise, indifference, embarrassment, discomfort and disgust.

Fathers were also asked to rate how comfortable they would feel if their own partner breast-fed in public in the same manner as the woman in the photograph. The possible answers were: completely comfortable with no concerns; fairly comfortable but with a few concerns; or completely uncomfortable with a lot of concerns. If fathers felt any degree of concern over their partner breast feeding in public, they were asked to specify the nature of their concern.

Socio-demographic data was also obtained from fathers, including parity, age, nationality, marital status, educational attainment and employment status.

\section{Steps taken to help improve questionnaire response rate}

Fathers were greeted by their first name in the letter which was included to explain the questionnaire. Each letter was signed by the first author. The letter briefly outlined the value of the questionnaire and provided a realistic estimate of the time needed (approximately ten minutes) to complete the questionnaire. Fathers could not be identified from the questionnaire or the return envelope, and so fathers were assured that their responses were anonymous.

A pen and a stamped addressed envelope were included to make questionnaire completion more convenient. Questionnaires were personally addressed to fathers and were delivered by standard post early in the working week (Mondays or Tuesdays). Fathers were given approximately two months to return the questionnaire.

No incentives were used, and due to the anonymous return of questionnaires, no reminders to complete the questionnaire were issued.

\section{Data handling and analysis}

Data were entered into the International Business Machines Corporation (IBM) Statistical Package for the Social Sciences (SPSS) for Windows, version 22.0 (IBM, Armonk, New York, United States). Normally distributed data on age and parity were summarised numerically using the mean \pm standard deviation. Data obtained from closed-ended questions were presented using frequencies and associated percentages.

The answers to open-ended questions were analysed using content analysis (Sandelowski, 2010). Content analysis presents a description of, and puts into context, what respondents said without drawing deep implications from the data. To analyse the answers to open questions, the researcher took a sample of 60 questionnaires and read the answers given for each open question on breast feeding. From this assessment, a list of frequently recurring themes was devised from the answers to each open-ended question. For example, the 'difficulty encountered by partner when establishing breast feeding' and the 'time commitment required to breast feed' were recurring themes amongst the answers given to the question on aspects of breast feeding for which fathers felt unprepared.

A numerical code was assigned to each theme listed. When a theme occurred amongst the answers given in later questionnaires, the numerical code for that theme was assigned to the answer given. The numerical codes were then entered into SPSS and quantitatively counted. Final themes were presented as frequencies and percentages. Answers from fathers which best described a particular theme were used to illustrate the final frequencies and percentages given.

\section{Findings}

Five hundred and eighty-three questionnaires were returned, giving a $42 \%$ response rate. The majority $(71.5 \%, n 417)$ of fathers who returned a questionnaire had a partner who initiated breast feeding. The results which follow relate to the 417 fathers with a breast-feeding partner. Table 1 summarises the socio-demographic characteristics of respondents.

The mean age of fathers was 36.3 ( $S D \pm 4.7$ ) years and the majority $(62.6 \%, n 261)$ had at least one other child (mean 1.6 other children). Most fathers had completed a college degree $(76.7 \%$, $n 320)$ and were in full-time employment $(91.6 \%, n 382)$. Most fathers were married $(87.8 \%, n 366)$, and of the fathers who were not married $(12.2 \%, n 51)$, only half $(49.0 \%, n 25)$ had guardianship rights over their child.

\section{Preparation and support for breast feeding}

Over three-quarters $(75.5 \%, n 315)$ of fathers were involved in the breast feeding decision. Most of these fathers $(72.7 \%, n 229)$ encouraged their partner to breast feed, while 6.7\% (n21) discouraged breast feeding. A fifth $(20.6 \%, n 65)$ of fathers reported discussing breast feeding without actively influencing their partner, thus ultimately leaving the final decision with her.

The most important sources of information on breast feeding were: past experience of having a breast-feeding partner $(30.0 \%$, $n 125)$; their partner's instructions $(26.9 \%, n 112)$; a lactation consultant $(8.4 \%, n 35)$; and the internet $(7.4 \%, n 31)$. Almost one in

Table 1

Socio-demographic characteristics of 417 fathers in Ireland with a breast-feeding partner.

\begin{tabular}{|c|c|c|c|}
\hline & & $\%$ & $n$ \\
\hline \multirow[t]{2}{*}{ Parity } & First-time father & 37.4 & 156 \\
\hline & Not a first-time father & 62.6 & 261 \\
\hline \multirow[t]{6}{*}{ Age (years) } & $\leq 24$ & 0.7 & 3 \\
\hline & $25-29$ & 4.1 & 17 \\
\hline & $30-34$ & 32.4 & 135 \\
\hline & $35-39$ & 41.0 & 171 \\
\hline & $40-44$ & 17.5 & 73 \\
\hline & $\geq 45$ & 4.3 & 18 \\
\hline \multirow[t]{3}{*}{ Nationality } & Irish & 97.4 & 406 \\
\hline & British & 1.7 & 7 \\
\hline & Other & 0.9 & 4 \\
\hline \multirow{3}{*}{ Marital status } & Married & 87.8 & 366 \\
\hline & Cohabiting & 12.0 & 50 \\
\hline & Not living with partner & 0.2 & 1 \\
\hline \multirow{5}{*}{ Education } & No formal education & 0.2 & 1 \\
\hline & $\begin{array}{l}\text { Primary and secondary } \\
\text { school }\end{array}$ & 13.7 & 57 \\
\hline & Vocational qualification & 9.4 & 39 \\
\hline & College degree & 33.3 & 139 \\
\hline & Postgraduate qualification & 43.4 & 181 \\
\hline \multirow[t]{5}{*}{ Employment status } & Stay-at-home dad & 0.7 & 3 \\
\hline & Working full-time & 91.6 & 382 \\
\hline & Working part-time & 4.1 & 17 \\
\hline & Unemployed & 3.4 & 14 \\
\hline & Student & 0.2 & 1 \\
\hline \multirow{2}{*}{$\begin{array}{l}\text { Formula-fed by time of } \\
\text { questionnaire }\end{array}$} & Yes & 86.6 & 361 \\
\hline & No & 13.4 & 56 \\
\hline
\end{tabular}


eight fathers $(12.9 \%, n 54)$ reported not feeling any need for information on breast feeding.

The majority $(56.8 \%, n 237)$ of fathers reported that their partner experienced some difficulty breast feeding. Of these, half $(50.6 \%, n 120)$ had enough information to help their partner to overcome her breast feeding difficulties and half $(49.4 \%, n 117)$ did not.

Almost half $(49.9 \%, n 208)$ of fathers were able to suggest types of information which they believed would have made breast feeding easier for their partner (Table 2). The most commonly cited $(45.2 \%, n 94)$ type of preferred information was consistent practical advice on how to troubleshoot issues which most often affect breast feeding, to include latching difficulties, blocked ducts, mastitis, tongue tie and maternal diet.

Other types of information which fathers (12.5\%, n26) felt would have made breast feeding easier included knowing how to: support their partner when breast feeding was unsuccessful; wean an infant off the breast; and manage feelings of jealousy or exclusion over the mother-infant bond created by breastfeeding.

\section{Unexpected aspects of breast feeding}

Over three-quarters $(77.5 \%, n 323)$ of fathers described aspects of breast feeding for which they were unprepared (Table 3 ). The most common $(52.6 \%, n 170)$ of these was the difficulty their partner encountered in learning to breast feed; that breast feeding did not "just happen."

Fathers were also taken aback by the: lack of readily available professional support; possibility of combination feeding; intensity of the mother-infant bond; and the number of calories burned by breast feeding.

\section{Perceived advantages to having a breast-feeding partner}

Of the fathers who listed advantages to having a breast-feeding partner $(86.8 \%, n 362)$, the most common advantages included the: health benefits for their infant $(49.4 \%, n 179)$; not having to do night feeds $(38.7 \%, n 140)$; the convenience of breast feeding compared to formula-feeding $(30.4 \%, n 110)$; and the strength of the mother-infant bond $(17.4 \%, n 63)$.

Other advantages included: having more time to care for other children or do household tasks; positive health benefits for their partner; their partner regaining her pre-pregnancy body shape more quickly; and the larger size of their partner's breasts.

of the 417 fathers with a breast-feeding partner, a small number $(6.2 \%, n 26)$ stated that they experienced no advantages to having a breast-feeding partner.

Perceived disadvantages to having a breast-feeding partner

While $12.7 \%$ (n53) of fathers reported no disadvantages to

Table 2

Most common types of information which a sample of 208 fathers in Ireland felt would have made breast feeding easier for their partner.

\section{$\% \quad N \quad$ Typical quote}

Consistent practical advice and assistance from the outset Being aware, before birth, of the time commitment and potential dif-
ficulties associated with establishing breast feeding

Understanding the production of adequate volumes of breast milk

Clearer understanding of the role of the father in breast feeding

Having non-judgemental individuals with whom to discuss breastfeeding
45.294 “A 'Top Tips' leaflet would be beneficial, with a section on 'What to do when [insert difficulty]..."

"Proper information in hospital - every midwife gave conflicting information. A lactation consultant visit should be mandatory for every breastfeeding mum."

"All of the different positions to breastfeed. My wife found that lying down on the bed with the baby was the easiest way to start."

22.647 "Knowing that just because you were able to do it first time around doesn't mean it will be easy or easier the second time around."

"Going to a breastfeeding class during the pregnancy, so that the difficulties were less of a shock."

10.121 "If I had known that allowing formula feeding too soon was the death knell for breastfeeding, I would have tried to help more and fight for it." "Understanding timings with supply and when to feed to keep supply going."

5.311 "I think fathers should be encouraged to attend any groups or consultants regarding breastfeeding, I feel it is a 'woman's world' when it comes to these things." "Knowing how I was meant to support her when there were problems or when she was finding it tough-going."

4.3 9 "She was called 'earth mother' by other women, so maybe educate the rest of the country to remove the stigma."

"A lack of the almost religious-like devotion to the cause of breastfeeding would have helped - a more balanced approach."

Table 3

Most common aspects of breast feeding for which 323 fathers in Ireland felt unprepared.

\begin{tabular}{|c|c|c|c|}
\hline & $\%$ & $N$ & Typical quote \\
\hline $\begin{array}{l}\text { Difficulty encountered by partner when establishing } \\
\text { breast feeding }\end{array}$ & 52.6 & 170 & $\begin{array}{l}\text { "The lack of honesty about how difficult and painful it is, that it's not a straightforward choice." } \\
\text { "The damage caused to breasts - her nipples cracked and her ducts got blocked." } \\
\text { "It's very difficult for something that should come naturally - it's physically and emotionally draining. It } \\
\text { takes time to master the art of breastfeeding." }\end{array}$ \\
\hline $\begin{array}{l}\text { Time commitment required by their partner to breast } \\
\text { feed }\end{array}$ & 18.6 & 60 & $\begin{array}{l}\text { "The constant feeding - up to } 12 \text { hours a day for } 12 \text { weeks." } \\
\text { "How time-consuming it was at the start - it was all we talked about for weeks." }\end{array}$ \\
\hline The bond between mother and infant & 12.1 & 39 & "How comforting both my wife and baby found it." \\
\hline The methods of producing breast milk & 5.6 & 18 & $\begin{array}{l}\text { "That if she wanted to express, it helped if she just thought about feeding the baby!" } \\
\text { "That a breast pump does not get as much milk as the baby would when he's feeding." }\end{array}$ \\
\hline $\begin{array}{l}\text { Feelings of exclusion due to infant's dependence on } \\
\text { mother }\end{array}$ & 3.1 & 10 & $\begin{array}{l}\text { "I was not expecting to be so unneeded." } \\
\text { "Less included - I felt like I was sitting on the outside looking in." }\end{array}$ \\
\hline
\end{tabular}


Table 4

Common disadvantages to having a breast-feeding partner experienced by a sample of 324 fathers in Ireland.

\begin{tabular}{|c|c|c|c|}
\hline & $N$ & $\%$ & Typical quote \\
\hline $\begin{array}{l}\text { Coping with the effects that full responsibility for feeding can have on a } \\
\text { mother }\end{array}$ & 190 & 58.6 & $\begin{array}{l}\text { "Wife is tired and grumpy from never getting } 8 \text { hours of straight sleep." } \\
\text { "It was so hard on her. It wore her down. I hated seeing her so stressed, strapped } \\
\text { to that breast pump for weeks." }\end{array}$ \\
\hline Less opportunities to bond with infant & 133 & 41.0 & $\begin{array}{l}\text { "Building a bond with the baby. I was left out on the edges a little." } \\
\text { "Breastfeeding forces the Dad out of an important and rewarding job." }\end{array}$ \\
\hline Anxiety over the success of breast feeding & 53 & 16.4 & $\begin{array}{l}\text { "Our uncertainty over how much the baby was consuming, even with lots of } \\
\text { solid nappies." } \\
\text { "My partner felt like a failure every time she made a bottle of formula." } \\
\text { "My wife was unable to breastfeed for more than a couple of days. She took this } \\
\text { inability very hard and saw herself as a failure. I deeply resent the "breast is best' } \\
\text { campaign and the detrimental effect it has on those unable to breastfeed, } \\
\text { especially as pregnancy leaves women very tired emotionally and physically." }\end{array}$ \\
\hline $\begin{array}{l}\text { Less regular routine (e.g. due to unpredictable feeding patterns, frequent night } \\
\text { feeds, or difficulties leaving the house if partner is uncomfortable feeding in } \\
\text { public) }\end{array}$ & 47 & 14.5 & $\begin{array}{l}\text { "Wife can't stay out for too long without bringing a pump, and her handbag is } \\
\text { full enough anyway." } \\
\text { "Some people can act very strangely if a woman breastfeeds in public, so it's } \\
\text { hard for her to breastfeed outside the house." }\end{array}$ \\
\hline
\end{tabular}

having a breast-feeding partner, most fathers $(77.7 \%, n 324)$ with a breast-feeding partner listed at least one disadvantage (Table 4). The most common disadvantage $(58.6 \%, n 190)$ was being unable to assist with feeding and coping with the resultant effects (e.g. tired, weepy, cantankerous) that this could have on their partner's emotional state. Other disadvantages included: decreased intimacy with partner; feelings of jealousy over the mother-infant bond; and managing sibling rivalry for maternal attention.

Two-fifths $(41.0 \%, n 133)$ of fathers felt concern regarding their opportunities to bond with their infant. To compensate for the lack of feeding time, fathers engaged in other bonding activities with their infant, to include: playing, reading, massage, doing skin-toskin, chatting, swimming, and going on walks.

Views on breast feeding in public

All fathers ( $n 417$ ) were asked about their predominant feeling to seeing a woman who was not their partner breast-feed in public. The majority of fathers $(56.6 \%, n 236)$ reported that they would feel indifferent and almost a third $(32.1 \%, n 134)$ reported that they would feel respect for a woman unrelated to them breast feeding in public. Almost one in ten $(9.4 \%, n 39)$ reported feeling uncomfortable and a small number $(1.9 \%, n 8)$ of fathers reported feeling surprise at seeing a woman breast-feed in public.

When fathers were asked about their reaction should their own partner ever breastfeed in public, the majority of fathers $(65.7 \%$, $n 274$ ) reported that they would be completely comfortable with this. Almost a third $(30.9 \%, n 129)$ reported that they would be fairly comfortable with a few concerns, while just $3.4 \%$ (n14) of fathers stated they would be completely uncomfortable with a lot of concerns were their partner ever to breast feed in public. The specific types of concerns held by fathers are listed in Table 5.

\section{Discussion}

With breastfeeding initiation and maintenance rates amongst Irish mothers being some of the lowest globally (Gallagher et al., 2015), ongoing investigation into breastfeeding support for women in Ireland is warranted. Fathers can provide a continuity of care which other sources of breastfeeding support cannot, and it is therefore important to heed the views and concerns of fathers in Ireland on their role in breastfeeding. The findings of this study indicate that while fathers are largely supportive of the concept of breast feeding, significant challenges remain in terms of the ability of fathers to support breast feeding in an informed and practical manner.

In terms of supporting mothers to initiate breastfeeding, the majority of fathers in this study reported encouraging their partner to breast feed. Paternal support has been repeatedly shown to affect the decision to initiate and maintain breast feeding (Scott et al., 1997; Binns and Scott, 2002; Hauck, 2004; Pisacane et al., 2005; Pontes et al., 2008). For example, Wolfberg et al. (2004) reported that women whose partner had attended a breast feeding class with other fathers during pregnancy were significantly more likely to initiate breast feeding compared to a control group. Scott et al. (2001) reported that women who perceived that their partner was supportive of breast feeding were 11 times more likely to

Table 5

Concerns held by a sample of 143 fathers in Ireland should their partner ever breast feed in public.

\begin{tabular}{|c|c|c|c|}
\hline & $\%$ & $n$ & Typical quote \\
\hline $\begin{array}{l}\text { Other people staring at partner's breasts during } \\
\text { feeding }\end{array}$ & 35.0 & 50 & $\begin{array}{l}\text { "Some young lads or perverts taking a sneaky look at her." } \\
\text { "Boobs on display for other people." } \\
\text { "That people might stare at her." }\end{array}$ \\
\hline $\begin{array}{l}\text { Causing offence or discomfort to other people in the } \\
\text { vicinity }\end{array}$ & 32.9 & 47 & $\begin{array}{l}\text { "Other people not approving or frowning upon it." } \\
\text { "Paranoid that other blokes would feel uncomfortable." } \\
\text { "It's uncomfortable for everyone around." }\end{array}$ \\
\hline Feeding is not discreet enough & 20.3 & 29 & $\begin{array}{l}\text { "Dignity of mother in an exposed situation." } \\
\text { "We have a very strange society where social networks rule. I would be afraid of someone filming and } \\
\text { putting it on the internet. I also think that it's a private thing." } \\
\text { "I would prefer if it was done discreetly. I don't think it's appropriate to be doing it in public, but if you need } \\
\text { to, cover it up." }\end{array}$ \\
\hline $\begin{array}{l}\text { Inappropriate comments which make partner feel } \\
\text { uncomfortable }\end{array}$ & 12.6 & 18 & "That ignorant people may say something and make her feel uncomfortable." \\
\hline
\end{tabular}


breast feed on discharge from hospital, and mothers who have an informed partner who is supportive of breast feeding are significantly more likely to successfully cope with breast feeding difficulties in the early postpartum period (Pisacane et al., 2005). Therefore, paternal support has been associated with improved rates of breast feeding initiation (Arora et al., 2000; Wolfberg et al., 2004), breast feeding upon hospital discharge (Scott et al., 2001), and breast feeding duration (Ingram and Johnson, 2004; Pisacane et al., 2005; Nickerson et al., 2012; Maycock et al., 2013).

Once breast feeding commenced, however, over three-quarters of fathers in this study reported feeling unprepared for different aspects of breastfeeding. Most commonly, fathers were unprepared for the difficulty and pain that their partner experienced during breast feeding, with half of fathers being unable to help their partner overcome breast feeding challenges when she experienced them.

Perceived milk insufficiency is the most common reason given for the cessation of breast feeding amongst Irish mothers (Layte and McCrory, 2014). Educating fathers on how to troubleshoot common breast feeding challenges has been associated with higher breast feeding rates at six months post partum (Scott et al., 2001; Pisacane et al., 2005). Ingram and Johnson (2004) reported that a 30-minute information session with both parents based on a leaflet containing practical breast feeding advice significantly increased breast feeding duration compared to controls, with most fathers reporting that they referred back to the leaflet after the session. Pisacane et al. (2005) reported that the delivery of 40 minutes of breast feeding education to groups of fathers in the antenatal period increased breast feeding duration and resulted in significantly lower rates of perceived milk insufficiency. Another intervention study (Tohotoa et al., 2010) found that 60 minutes of antenatal breast feeding education helped fathers to develop more realistic expectations of feeding and to acquire practical knowledge on ways to manage the challenges of breast feeding.

Irish maternity hospitals currently do not provide fathers with dedicated instruction on breast feeding. However, with a mother's typical hospital stay being less than 2 days (Coombe Women and Infants University Hospital, 2013), fathers are a potentially invaluable source of support to help sustain feeding in the early postpartum period, especially when a mother's milk supply is not yet established. Since pregnancy is a unique time during which both parents are simultaneously in contact with health professionals over the care of their child, engaging more closely with fathers to promote breast feeding is an important consideration for maternity services.

Fathers in this study clearly identified advantages to breastfeeding and expressed the desire to meaningfully help their partner to breast feed. Fathers wanted practical feeding information, not only on fundamental aspects of feeding such as optimal feeding positions and factors which affect milk production, but also on helpful ways to emotionally support their breast-feeding partner. The means by which fathers can help their breast-feeding partner may not be immediately apparent to them (Henderson et al., 2011; Sherriff and Hall, 2011), and providing guidance on useful types of support may help fathers to feel more included and competent when it comes to the care of their infant (Ingram and Johnson, 2004; Brown and Davies, 2014). Preferred forms of practical support reported by mothers include cooking, doing housework, caring for other children, bathing the infant, bringing infant to mother for night feeds and helping the mother to relax (Tohotoa et al., 2009; Rempel and Rempel, 2011). Helpful emotional supports include praise for her breast feeding efforts, compliments on her progress with breast feeding, and defending the mother from individuals advocating formula feeding (Tohotoa et al., 2009; Rempel and Rempel, 2011; Nickerson et al., 2012).

Alongside helping their partner to succeed with breastfeeding and their mothering role, fathers also wanted to flourish in their fathering role and develop a strong relationship with their infant. Despite all fathers identifying bonding activities which help them to compensate for not feeding their infant, a significant minority of fathers expressed concerns about the perceived impact of feeding deprivation on the father-infant bond, a finding reported elsewhere (Goodman, 2005; Rempel and Rempel, 2011; Nickerson et al., 2012). As men frequently report feeling helpless during pregnancy and childbirth (Dellman, 2004; Longworth and Kingdon, 2011), it is unsurprising that they wish to have an active role with the essential task of feeding. Fathers of breast-fed infants often feel alienated from the mother-infant bond that forms (Barclay and Lupton, 1999; Goodman, 2005) and jealous of the privileged position a breast-feeding mother holds as the sole food provider (Rempel and Rempel, 2011; Nickerson et al., 2012). However, the intimacy created by breast feeding cannot be replicated with bottle-feeding, so fathers won't necessarily enjoy the same closeness when feeding their infant as a mother does. Therefore, fathers should be reassured that they can still develop a warm and nurturing role as the non-food parent without compromising the frequency or duration of breast feeding. To help promote this, health professionals should reiterate the value of a father to the success of breast feeding and provide unambiguous advice to both parents on how a father can be meaningfully involved in the feeding process.

The need for consistent advice on breast feeding from health professionals was emphasised in this study. Inconsistent advice from health professionals has been reported to stymie the efforts of fathers in supporting breast feeding (Brown and Davies, 2014; Whelan and Kearney, 2014; Hunter et al., 2015). A more concerted effort on the part of health professionals to include fathers may be encouraged if the role of fathers in breast feeding is more explicitly acknowledged in national strategies and policies. For example, the most recent Irish breast feeding strategy (Department of Health and Children, 2005) refers to the need to include partners in the maternal breast feeding network, but does not specify how this is to be done. Since the two main disadvantages to having a breastfeeding partner in this study related to being unable to adequately support their partner and feeling deprived of bonding time, the value and role of fathers in the maternal breast feeding network should be clearly conveyed throughout pregnancy and the postpartum period.

It is of note that while one in ten fathers reported feeling discomfort with an unrelated woman breast feeding in public, this increased to three in ten if the woman in question was their partner. The main reasons for feeling discomfort included possible infringements upon their partner's modesty and causing offence to those in the surrounding environ. Importantly, the concerns of fathers in this study regarding breast feeding in public are not dissimilar to the concerns voiced by mothers in other studies (Sheeshka et al., 2001; Ahluwalia et al., 2005; Keely et al., 2015). This restrictive attitude towards breast feeding in public does not always indicate a lack of support for breast feeding (Scott et al., 1997; Spurles and Babineau, 2011; Vieth et al., 2016). Rather, there seems to be a conflict between balancing conservative cultural and social norms with the naturally intimate process of breast feeding.

Social support and cultural norms significantly affect the initiation and duration of breast feeding (Li et al., 2002; McFadden and Toole, 2006; Brown et al., 2011; Boyer, 2011; Vari et al., 2012). Ireland has a strong formula feeding culture (Carroll et al., 2015), where breastfeeding beyond the first few weeks post partum has been marginal for several generations (Curtin, 1954; Kevany et al. 1975; McSweeney and Kevany, 1982; Fitzpatrick et al., 1994; Brick and Nolan, 2013). As such, the general population has scant exposure to women breast feeding in public. 
Women have reported feeling vulnerable and embarrassed while breast feeding in public (Earle, 2002; Begley et al., 2008), even in the absence of negative attention (Sheeshka et al., 2001). Negative reactions to unfamiliar practices are to be expected; what is important to note is that such reactions generally become more positive with increased familiarity (Greene et al., 2003; Spurles and Babineau, 2011). Therefore, an environment which promotes breast feeding as an essential everyday activity can foster a more tolerant attitude towards breast feeding in public. However, normalising breastfeeding in a country with an embedded formula feeding culture will require extensive promotion of breast feeding within schools, colleges, health services, workplaces, businesses and public spaces. Furthermore, pregnant women should be informed about their right to breast feed in public and can be given advice on how to breast feed discreetly to bolster their confidence in their ability to breast feed in public (Sheeshka et al., 2001).

Before drawing final conclusions on the findings of this study, the methodological strengths and limitations must be considered.

Postal questionnaires have an average response rate of approximately 56\% (Nulty, 2008). Strategies to increase questionnaire response rates in this study included: personally addressed envelopes; personalised hand-signed letters; the use of coloured ink; the inclusion of a stamped addressed envelope and pen; the use of a university logo; providing assurance of anonymity; and the inclusion of an acceptable number of questions (Edwards et al., 2002; Nulty, 2008). Despite these measures being taken, this questionnaire had a below-average response rate of $42 \%$. While this response rate is less than anticipated, the sample size of 417 questionnaires was adequate for analysis, and the group of fathers to which the results best apply is known from the socio-demographic data collected.

From the sociodemographic data collected, this questionnaire represents fathers who are more educated and have a lower rate of unemployment compared to the national population. The breast feeding initiation rate of $71.5 \%$ reported in this questionnaire was also higher than the breast feeding initiation rate of $61.2 \%$ reported by the Coombe Women and Infants University Hospital in 2013 (Coombe Women and Infants University Hospital, 2013). Furthermore, respondents were self-selected and in light of the topic being investigated, may have been biased towards providing responses perceived as socially desirable. However, the anonymity of the questionnaire should have encouraged a more frank expression of views held on breast feeding (Lippitt et al., 2014).

While this study does not represent younger or less welleducated fathers, it is one of the first studies in Ireland to provide important insights on breast feeding from well-educated fathers who are in stable relationships and who are actively involved in the upbringing of their children.

Future research should investigate the views of younger fathers and fathers from more disadvantaged backgrounds, and should identify alternative ways of encouraging men in Ireland to take part in research related to fatherhood.

Despite the undisputed benefits of breastmilk (Gartner et al., 2005), the rate of breast feeding in Ireland remains low by international standards (Brick and Nolan, 2013). The increase in rates of breast feeding in recent years is largely due to non-modifiable maternal trends, such as increasing maternal age and higher numbers of non-national women giving birth here (Brick and Nolan, 2013). Therefore, existing policy initiatives have been largely ineffective in creating a more balanced infant feeding culture amongst Irish women. Fathers play a critical role in providing support to mothers and infants, and the lack of meaningful engagement with fathers and fathers-to-be is a missed opportunity for breast feeding promotion. The core of a breast feeding family consists of mother, infant and father, and all three must be recognised as the cornerstones of successful breast feeding. If fathers are more effectively included in the breast feeding process, mothers will feel better supported, fathers will feel less excluded, and infants will reap the benefits of an environment in which breast feeding is the norm.

\section{Conflict of interest}

The authors report no conflict of interest.

\section{Acknowledgements}

We would like to thank all the fathers who kindly completed the survey and shared their experiences of the early postpartum period.

AEB was supported by a Dublin Institute of Technology Fiosraigh Scholarship which is funded by Dublin Institute of Technology and Danone Nutricia (PB03874). Danone Nutricia had no role in the: study design; collection, analysis, and interpretation of data; writing of the manuscript; and decision to submit the manuscript for publication.

AEB was responsible for study design, data collection, data analysis, drafting the manuscript, and making critical amendments to the manuscript. DM and JMK were the study supervisors and were responsible for manuscript revision.

\section{References}

Ahluwalia, I.B., Morrow, B., Hsia, J., 2005. Why do women stop breastfeeding? Findings from the Pregnancy Risk Assessment and Monitoring System. Pediatrics 116, 1408-1412.

Arora, S., McJunkin, C., Wehrer, J., Kuhn, P., 2000. Major factors influencing breastfeeding rates: mother's perception of father's attitude and milk supply. Pediatrics 106, e67.

Barclay, L., Lupton, D., 1999. The experiences of new fatherhood: a socio-cultural analysis. Journal of Advanced Nursing 29, 1013-1020.

Begley, C., Gallagher, L., Clarke, M., Carroll, M., Millar, S., 2008.The National Infant Feeding Survey 2008 [Online]. Available from: 〈https://www.breastfeeding.ie uploads/files/National_Infant_Feeding_Survey_2008.pdf) [04 January 2016].

Binns, C.W., Scott, J.A., 2002. Breastfeeding: reasons for starting, reasons for stopping and problems along the way. Breastfeeding Review 10, 13-19.

Boyer, K., 2011. "The way to break the taboo is to do the taboo thing" breastfeeding in public and citizen-activism in the UK. Health and Place 17, 430-437.

Brick, A., Nolan, A., 2013. Explaining the increase in breastfeeding at hospital discharge in Ireland, 2004-2010. Irish Journal of Medical Science 183, 333-339.

Brown, A., Davies, R., 2014. Fathers' experiences of supporting breastfeeding: challenges for breastfeeding promotion and education. Maternal and Child Nutrition 10, 510-526.

Brown, A., Raynor, P. Lee, M., 2011. Young mothers who choose to breast feed: the importance of being part of a supportive breast-feeding community. Midwifery 27, 53-59.

Carroll, M., Gallagher, L., Clarke, M., Millar, S., Begley, C., 2015. Artificial milkfeeding women's views of their feeding choice in Ireland. Midwifery 31, 640-646.

Coombe Women and Infants University Hospital, 2013. Annual Clinical Report 2013 [Online]. Available from: 〈http://www.drugsandalcohol.ie/23761/1/COOMBE\% 20ANNUAL\%20REPORT\%202013.pdf $\rangle$. [05 January 2016].

Curtin, M., 1954. Failure to breastfeed: a review of the feeding history of 1007 infants. Irish Journal of Medical Science 29, 447-446.

Dellman, T., 2004. "The best moment of my life": a literature review of fathers' experience of childbirth. Australian Journal of Midwifery 17, 20-26.

Department of Health, 1994. A National Breastfeeding Policy for Ireland. Department of Health, Dublin.

Department of Health and Children, 2005. Breastfeeding in Ireland: A Five-Year Strategic Action Plan. Department of Health and Children, Dublin.

Earle, S., 2002. Factors affecting the initiation of breastfeeding: implications for breastfeeding promotion. Health Promotion International 17, 205-214.

Edwards, P., Roberts, I., Clarke, M., et al., 2002. Increasing response rates to postal questionnaires: a systematic review. British Medical Journal 324, 1183-1191.

Fitzpatrick, C.C., Fitzpatrick, P.E., Darling, M.R.N., 1994. Factors associated with the decision to breastfeed among Irish women. Irish Medical Journal 87, 145-146.

Gallagher, L., Begley, C., Clarke, M., 2015. Determinants of breastfeeding initiation in Ireland. Irish Journal of Medical Science 〈http://link.springer.com/article/10. 1007\%2Fs11845-015-1333-2> [08 January 2016]. 
Gartner, L.M., Morton, J., Lawrence, R.A., et al., 2005. Breastfeeding and the use of human milk. Pediatrics 115, 496-506.

Goodman, J.H., 2005. Becoming an involved father of an infant. Journal of Obstetric, Gynecologic and Neonatal Nursing 34, 190-200.

Greene, J., Stewart-Knox, B., Wright, M., 2003. Feeding preferences and attitudes to breastfeeding and its promotion among teenagers in Northern Ireland. Journal of Human Lactation 19, 57-65.

Hauck, Y.L., 2004. Factors influencing mothers' decision to breastfeed in public Breastfeeding Review 12, 15-23.

Henderson, L., McMillan, B., Green, J.M., Renfrew, M.J., 2011. Men and infant feeding: perceptions of embarrassment, sexuality, and social conduct in white lowincome British men. Birth 38, 61-70.

Hunter, L., Magill-Cuerden, J., McCourt, C., 2015. 'Oh no, no, no, we haven't got time to be doing that': challenges encountered introducing a breast-feeding support intervention on a postnatal ward. Midwifery 31, 798-804.

Ingram, J., Johnson, D., 2004. A feasibility study of an intervention to enhance family support for breast feeding in a deprived area in Bristol, UK. Midwifery 20, 367-379.

Keely, A., Lawton, J., Swanson, V., Denison, F.C., 2015. Barriers to breast-feeding in obese women: a qualitative exploration. Midwifery 31, 532-539.

Kenosi, M., Hawkes, C.P., Dempsey, E.M., Ryan, C.A., 2011. Are fathers underused advocates for breastfeeding? Irish Medical Journal 104, 313-315.

Kevany, J., Taylor, M., Kaliszer, M., et al., 1975. Influences on choice of infant feeding methods. Journal of the Irish Medical Association 68, 499-505.

Layte, R., McCrory, C., 2014. Maternal Health Behaviours and Child Growth in Infancy: Analyses of the Infant Cohort of the Growing Up in Ireland Study. The Stationery Office, Dublin, pp. 39-52.

Li, R., Fridinger, F., Grummer-Strawn, L., 2002. Public perceptions on breastfeeding constraints. Journal of Human Lactation 18, 227-235.

Lippitt, M., Reese Masterson, A., Sierra, A., Davis, A.B., White, M.A., 2014. An exploration of social desirability bias in measurement of attitudes toward breastfeeding in public. Journal of Human Lactation 30, 358-366.

Longworth, H.L., Kingdon, C.K., 2011. Fathers in the birth room: what are they expecting and experiencing? A phenomenological study. Midwifery 27, 588-594.

Maycock, B., Binns, C.W., Dhaliwal, S., et al., 2013. Education and support for fathers improves breastfeeding rates: a randomised controlled trial. Journal of Human Lactation 29, 484-490.

McFadden, A., Toole, G., 2006. Exploring women's views of breastfeeding: a focus group study within an area with high levels of socio-economic deprivation. Maternal and Child Nutrition 2, 156-168.

McSweeney, M., Kevany, J., 1982. Infant Feeding Practices in Ireland. Health Education Bureau, Dublin, pp. 15-26.

Nickerson, L.E., Sykes, A.C., Fung, T.T., 2012. Mothers' experience of fathers' support for breastfeeding. Public Health Nutrition 15, 1780-1787.

Nulty, D.D., 2008. The adequacy of response rates to online and paper surveys: what can be done? Assessment and Evaluation in Higher Education 33, 301-314.

Pisacane, A., Continisio, G.I., Aldinucci, M., D'Amora, S., Continisio, P., 2005. A controlled trial of the father's role in breastfeeding promotion. Pediatrics 116, e494-e498.

Pontes, C.M., Alexandrino, A.C., Osório, M.M., 2008. The participation of fathers in the breastfeeding process: experiences, knowledge, behaviours and emotions.
Jornal de Pediatria 84, 357-364.

Pontes, C.M. Osório, M.M., Alexandrino, A.C. 2009. Building a place for the father as an ally for breastfeeding. Midwifery 25, 195-202.

Rempel, L.A., Rempel, J.K., 2011. The breastfeeding team: the role of involved fathers in the breastfeeding family. Journal of Human Lactation 27, 115-121.

Sandelowski, M., 2010. What's in a name? Qualitative description revisited. Research in Nursing and Health 33, 77-84.

Scott, J.A., Binns, C.W., Aroni, R.A., 1997. The influence of reported paternal attitudes on the decision to breastfeed. Journal of Paediatrics and Child Health 33, 305-307.

Scott, J.A., Landers, M.C.G., Hughes, R.M., Binns, C.W., 2001. Factors associated with breastfeeding at discharge and duration of breastfeeding. Journal of Paediatrics and Child Health 37, 254-261.

Sheeshka, J., Potter, B., Norrie, E., Valaitis, R., Adams, G., Kuczynski, L., 2001. Women's experiences breastfeeding in public places. Journal of Human Lactation $17,31-38$.

Sherriff, N., Hall, V., 2011. Engaging and supporting fathers to promote breastfeeding: a new role for Health Visitors? Scandinavian Journal of Caring Sciences $25,467-475$.

Spurles, P.K., Babineau, J., 2011. A qualitative study of attitudes toward public breastfeeding among young Canadian men and women. Journal of Human Lactation 27, 131-137.

Susin, L.R.O., Giugliani, E.R.J., 2008. Inclusion of fathers in an intervention to promote breastfeeding: impact on breastfeeding rates. Journal of Human Lactation 24, 386-392.

Tarrant, R.C., Younger, K.M., White, M., Kearney, J.M., 2009. The prevalence and determinants of breastfeeding initiation and duration in a sample of women in Ireland. Public Health Nutrition 13, 760-770.

Tarrant, R.C., Younger, K.M., Sheridan-Pereira, M., Kearney, J.M., 2011. Factors associated with duration of breastfeeding in Ireland: potential areas for improvement. Journal of Human Lactation 27, 262-271.

Tohotoa, J., Maycock, B., Hauck, Y., Howat, P., Burns, S., Binns, C.W., 2009. Dads make a difference: an exploratory study of paternal support for breastfeeding in Perth, Western Australia. International Breastfeeding Journal, 4. http://dx.doi. org/10.1186/1746-4358-4-15.

Tohotoa, J., Maycock, B., Hauck, Y., Howat, P., Burns, S., Binns, C., 2010. Supporting mothers to breastfeed: the development and process evaluation of a father inclusive perinatal education support program in Perth, Western Australia. Health Promotion International 26, 351-361.

Vari, P., Vogeltanz-Holm, N., Olsen, G., et al., 2012. Community breastfeeding attitudes and beliefs. Health Care for Women International 34, 592-606.

Vieth, A., Woodrow, J., Murphy-Goodridge, J., O'Neil, C., Roebothan, B., 2016. The ability of posters to enhance the comfort level with breastfeeding in a public venue in rural Newfoundland and Labrador. Journal of Human Lactation 32, 174-181.

Whelan, B., Kearney, J.M., 2014. Breastfeeding support in Ireland: a qualitative study of health-care professionals' and women's views. Public Health Nutrition 18, 2274-2282.

Wolfberg, A.J., Michels, K.B., Shields, W., O'Campo, P., Bronner, Y., Bienstock, J., 2004 Dads as breastfeeding advocates: results from a randomized controlled trial of an educational intervention. American Journal of Obstetrics and Gynecology 191, 708-712. 